\title{
OS REFLEXOS DA CONFERÊNCIA DE HAIA SOBRE DIREITO INTERNACIONAL PRIVADO EM RELAÇÃO À ANACIONALIDADE DECORRENTE DA MATERNIDADE DE SUBSTITUIÇÃO TRANSNACIONAL
}

\author{
THE REFLECTIONS OF THE HAGUE CONFERENCE ON PRIVATE LAW \\ IN RELATION TO NONNATIONALITY ARISING OUT OF \\ TRANSNATIONAL SUBSTITUTION MATERNITY
}

\author{
Taciana Damo Cervi \\ Universidade Regional Integrada do Alto Uruguai e das Missões - URI - (Santo Ângelo, RS, Brasil) \\ Sinara Camera \\ Faculdades Integradas Machado de Assis - Fema - (Santa Rosa, RS, Brasil)
}

Recebimento: 21 mar. 2017

Aceitação: 11 ago. 2017

\begin{abstract}
Como citar este artigo / How to cite this article (informe a data atual de acesso / inform the current date of access):
CERVI, Taciana Damo; CAMERA, Sinara. Os reflexos da Conferência de Haia sobre direito internacional privado em relação à anacionalidade decorrente da maternidade de substituição transnacional. Revista da Faculdade de Direito UFPR, Curitiba, PR, Brasil, v. 62, n. 3, p. 81-101, set./dez. 2017. ISSN 2236-7284. Disponível em: <http://revistas.ufpr.br/direito/article/view/51329>. Acesso $\quad$ em: 21 dez. $2017 . \quad$ DOI: http://dx.doi.org/10.5380/rfdufpr.v62i3.51329.
\end{abstract}

\section{RESUMO}

Esta pesquisa se debruça sobre a temática da maternidade de substituição no direito internacional privado e se justifica em razão do intenso progresso médico-científico na área e dos conflitos e lides propostas para o reconhecimento da nacionalidade de crianças oriundas dos procedimentos de maternidade substitutiva, dado que cada país legisla de acordo com a realidade nacional, necessitando-se discutir sobre a harmonização dos interesses no âmbito internacional. Assim, a pesquisa pretende questionar quais as contribuições da Conferência de Haia sobre Direito Internacional Privado para a harmonização dos ordenamentos jurídicos em matéria de maternidade de substituição e, especialmente quais os reflexos para o ordenamento jurídico brasileiro. Para tanto, investiga-se os avanços da técnica da reprodução humana medicamente assistida com foco na maternidade de substituição, de modo a averiguar como o direito comparado tem encontrado respostas para as questões oriundas do procedimento. Posteriormente, o estudo discorre sobre as disposições do direito brasileiro relacionado e o esforço internacional verificado pela Conferência de Haia. Ao final, o trabalho identifica que o direito interno sofre limitações para resolver os problemas oriundos da maternidade de substituição transnacional e, por isso, ressalta-se a necessidade de cooperação multilateral para que, em uníssono, sejam garantidos os direitos das crianças. Nesse aspecto, destacam-se os resultados práticos verificados a partir da Conferência de Haia na solução do problema da anacionalidade. A temática ainda impõe desafios para o futuro no que concerne ao tráfico de crianças, à vulnerabilidade das mulheres envolvidas na gestação de substituição e à própria onerosidade do contrato. 


\title{
PALAVRAS-CHAVE
}

Maternidade de substituição. Direito brasileiro. Direito comparado. Anacionalidade.

\begin{abstract}
This research focuses on the issue of surrogate motherhood in private international law and is justified because of intense medical and scientific progress in the area and conflicts and litigations proposals for recognition of the nationality of children from the surrogate motherhood procedures as each country legislates according to the national reality, requiring discussions about the harmonization of interests internationally. Thus, the research seeks to question the contributions of the Hague Conference on Private International Law to the harmonization of legal systems in the field of surrogacy and especially what are its effects to the Brazilian legal system. To this end, the first topic investigates advances in assisted human reproduction technique focusing on surrogacy in order to find out how comparative law has found answers to the questions arising from the procedure. Subsequently, the study focuses on the study of Brazilian law and the related international effort verified by the Hague Conference. Finally, the paper identifies the national law suffers limitations to solve the problems arising from transnational surrogacy, and therefore the need for multilateral cooperation is emphasized so that, in unison, children's rights are guaranteed. In this regard, we highlight the practical results obtained from the Hague Conference on resolving the problem of nonnationality. The theme also poses challenges for the future with regard to trafficking in children, the vulnerability of women involved in surrogate motherhood and the very burden of the contract.
\end{abstract}

\section{KEYWORDS}

Surrogate motherhood. Brazilian law. Comparative law. Nonnationality.

\section{CONSIDERAÇÕES INICIAIS}

A investigação sobre maternidade de substituição no direito internacional privado se justifica em razão do intenso progresso médico-científico na área e da facilitada mobilidade vivenciada pelas pessoas com maior capacidade econômica. Sobretudo, encontra justificativa nos conflitos e nas lides propostas para o reconhecimento da nacionalidade de crianças oriundas dos procedimentos de maternidade substitutiva, dado que cada país legisla de acordo com a sua realidade nacional. É preciso, portanto, discutir sobre a necessidade de harmonização dos interesses no âmbito internacional.

A pesquisa adota o método funcional de modo que, por meio da comparação, se buscará perceber semelhanças, mas principalmente distinções, entre os sistemas comparados. Ainda, por meio da microcomparação, pretende analisar o instituto da maternidade de substituição em diversos países, verificando quais são as suas diferenças. Nesses termos, o método assume novos contornos em um cenário de pós-modernidade, em que Erik Jayme (1999, 2003) propõe o paradigma da diferença, rompendo com o pensamento universal e a ideia de colonialismo. 
Assim, a teoria que embasa o trabalho é a de Erik Jayme (1999, 2003), que rompe com o pensamento universal por meio da investigação de diferenças entre os institutos, permitindo a verificação dos melhores contornos para o instituto no direito nacional. Nesse sentido, a pesquisa pretende questionar quais as contribuições da Conferência de Haia sobre Direito Internacional Privado para a harmonização dos ordenamentos jurídicos em matéria de maternidade de substituição e, especialmente, quais os reflexos para o ordenamento jurídico brasileiro.

Para tanto, o ensaio foi dividido em dois momentos: primeiramente, a investigação centra esforços na técnica da reprodução humana medicamente assistida, com foco na maternidade de substituição, de modo a averiguar como o direito comparado tem encontrado respostas para as questões oriundas do procedimento. Na segunda subseção, o estudo debruça-se sobre a análise da maternidade substitutiva no direito brasileiro e no direito internacional privado, notadamente no esforço internacional verificado na Conferência de Haia.

\section{MATERNIDADE DE SUBSTITUIÇÃO, SUB-ROGAÇÃO OU BARRIGA DE ALUGUEL}

A reprodução humana artificial, dita medicamente assistida, está na pauta das discussões do século XXI. A ânsia do homem em desafiar os limites do conhecido tem oportunizado à humanidade importantes conquistas, como a maternidade para mulheres estéreis, para mulheres de idade avançada que biologicamente não poderiam ter filhos e para casais homoafetivos (BRAUNER, 2003).

O estágio atual de medicalização da reprodução humana mostra a ideia de rompimento e separação entre reprodução humana e sexualidade. De acordo com Sandel (2013, p. 34), o aprimoramento da técnica permite também a intervenção nas características genéticas dos filhos, oportunizando a escolha do sexo e de características preferenciais dos genitores.

Os termos utilizados para nominar a técnica são: reprodução artificial, concepção artificial, fertilização artificial, fecundação ou fertilização assistida ou, ainda, reprodução humana medicamente assistida, termo utilizado nesta pesquisa. Nesse sentido, a prática é definida por Scarparo (1991, p. 242) como um "conjunto de técnicas que têm como fim provocar a gestação mediante a substituição ou facilitação de alguma etapa que se mostre deficiente no processo reprodutivo”, consistindo "no processo que leva o óvulo a entrar em contato com o espermatozoide, resultando um ser humano sem cópula carnal”.

A história da humanidade reflete as intenções do homem de efetivar projetos de maternidade e paternidade a partir de métodos pouco convencionais. Resgata-se o mito grego do nascimento de Perseu, em que Acrísio, rei de Argos, enclausurou sua filha Dânae, a mulher pretendida por Zeus, em 
uma câmara subterrânea, pois, de acordo com a profecia, o rei seria morto por seu neto. “Zeus, porém, sob a forma de chuva de ouro, penetrou, por uma fenda, no compartimento que parecia inviolável, e seduziu Dânae, que a ele se uniu e engravidou. Meses depois, nasceu Perseu” (DIAS; PITERI, 2010, p. 19).

Na Bíblia Sagrada, encontra-se o primeiro relato de maternidade de substituição no livro do Gênesis, capítulo 16, versículo 2, quando Sara constata sua esterilidade e sugere a Abraão que tome sua escrava Agar para gerar descendência (BÍBLIA SAGRADA, 2004).

Ainda, na Bíblia encontra-se o relato da concepção de Jesus sem a conjunção carnal de Maria e José. Segundo o evangelho de Lucas, 18, X, o anjo Gabriel disse a Maria: “Eis que engravidarás e darás à luz um filho, a quem chamarás pelo nome de Jesus”, e, no livro de Isaías, nota-se "Eis que a virgem ficará grávida e dará à luz um filho, e o Nome dele será Emanuel, Deus Conosco!” (BÍBLIA SAGRADA, 2004, grifo nosso).

Nesse sentido, e diante de tais circunstâncias, tradicionalmente o parto sempre foi o evento que definiu legalmente a maternidade. Gruenbaum (2012, p. 475, tradução nossa) refere que “tradicionalmente, de acordo com a lei, é o parto que pode conferir maternidade, porque ninguém mais poderia dar à luz à criança senão quem é a mãe”.

Contudo, a curiosidade do homem o levou a buscar os limites e testar sobre o desconhecido. A fábula de Aldous Huxley, “Admirável Mundo Novo”, publicada em 1932, descreve a criação de seres humanos em laboratórios, a partir de processos de fecundação artificial, inclusive com a criação de gêmeos, e delineia uma sociedade de castas por meio da intervenção científica para a produção de líderes, intelectuais e operários (HUXLEY, 2003).

Atualmente, a reprodução humana medicamente assistida é possível por muitos modos, utilizando as células germinativas das pessoas envolvidas no projeto parental, ou seja, óvulos e espermatozoides daqueles que naturalmente não conseguem ter filhos, o que é nominado fertilização homóloga; ou, com utilização de material genético de terceiros, nominada fertilização heteróloga (DINIZ, 2014).

As técnicas empregadas são diversas. Diniz (2014) destaca a inseminação artificial, caracterizada pela introdução do material genético masculino no corpo da mulher; ainda, há possibilidade de fertilização in vitro, em que a fecundação do óvulo acontece em laboratório, sendo o embrião introduzido no corpo da mulher em que será gestado. Essa técnica permite a fecundação a partir de óvulos e espermatozoides de terceiros.

No entendimento de Brauner (2011, p. 57), 
[...] embora seja a adoção uma experiência enriquecedora, devendo ser incentivada dia a dia, ela não representa o caminho escolhido por todos que não podem gerar naturalmente, pelo que deve ser dado reconhecimento aos métodos ofertados pela ciência moderna para tratar da infertilidade e da esterilidade, dado que a esterilidade não é aceita facilmente, razão pela qual mulheres estéreis se socorrem dos métodos de reprodução medicamente assistida, dentre as quais ganha relevância a gestação de substituição.

Com isso, Meirelles (1998) explica que a utilização deste método de reprodução artificial pode fazer surgir diferentes figuras de mãe; citem-se a mãe social, que assume a maternidade no sentido da criação do filho, a mãe genética, que doa seu óvulo para a fecundação, e a mãe biológica, que gesta a criança. Nesse sentido, ainda será possível que duas destas figuras estejam reunidas em uma só pessoa como no caso de a mãe genética ser também a mulher que gesta a criança.

É o que refere Schwenzer (apud ARAÚJO; VARGAS; MARTEL, 2014), com o conceito de maternidade cindida ou split motherhood, ou seja, o conceito de que a maternidade não é mais una, na medida em que há possibilidade de até três pretensões de maternidade: uma ancorada na gestação, outra na origem genética e outra, ainda, no projeto parental.

Como mencionado, a gestação por substituição traz importante repercussão sobre a determinação da maternidade. Há séculos compreende-se que não há dúvidas, em razão do parto, sobre quem é a mãe de uma criança. Todavia, as biotecnologias alteraram papéis, permitindo identificar a gestante como mãe biológica, a doadora do material genético como mãe genética e, ainda, a autora do projeto de maternidade como mãe afetiva.

Nesse aspecto, uma mulher que não pretende assumir a maternidade cede seu corpo para gestar uma criança para outrem. A literatura também denomina a referida técnica como “maternidade de sub-rogação” e, em alguns países, ela é conhecida como "barriga de aluguel”, caso em que há remuneração da gestante que presta o serviço de gestar criança para o solicitante.

Maternidade de substituição é definida por Dias (2013, p. 379) como a

[...] gestação por conta de outrem, maternidade por substituição ou sub-rogação são expressões que nada mais significam do que a conhecida barriga de aluguel. [...] A gestação por substituição seria um negócio jurídico de comportamento, compreendendo para a "mãe de aluguel” obrigações de fazer e não fazer, culminando com a obrigação de dar, consistente na entrega do filho.

Essa sub-rogação é realizada porque os pais por pretensão não podem ter filhos naturalmente. Destacam-se os casos em que homossexuais querem ter seus próprios filhos - o exemplo mais conhecido é o de Elton John e David Furnish, que têm dois filhos nascidos por meio da técnica (BENICKE, 2013).

Diante do êxito e difusão alcançado por ambas as técnicas, é indispensável que o processo mantenha, como objetivo precípuo, a promoção da dignidade da pessoa humana a todos os 
envolvidos: homens, mulheres e crianças reunidos pelo projeto de parentalidade. Dessa forma, é fundamental compreender-se que a dignidade da pessoa humana consiste na

[...] qualidade intrínseca e distintiva de cada ser humano que o faz merecedor do mesmo respeito e consideração por parte do Estado e da comunidade, implicando, neste sentido, um complexo de direitos e deveres fundamentais que assegurem a pessoa tanto contra todo e qualquer ato de cunho degradante e desumano, como venham a lhe garantir as condições existenciais mínimas para uma vida saudável, além de propiciar e promover sua participação ativa e co-responsável nos destinos da própria existência e da vida em comunhão com os demais seres humanos (SARLET, 2001, p. 60).

Portanto, as técnicas aqui referidas, enquanto projeto de parentalidade, devem reforçar a afirmação da dignidade dos seres humanos, constituindo-se em um verdadeiro limitador aos procedimentos científicos. Nesse mesmo sentido está a referência de Brauner (2003, p. 70), ao afirmar que:

As novas tecnologias reprodutivas oferecem uma gama de possibilidades à mulher e ao homem, envolvendo a possibilidade de realização do seu projeto de parentalidade, cabendo uma reflexão sobre quais os procedimentos que podem ser realizados sem afrontar diretamente os direitos fundamentais de cada um deles e, igualmente, da criança, que deve ter o direito de nascer com a dignidade devida a todos os seres humanos.

Nesse aspecto, é importante frisar que diante de todo o progresso científico na área e das inúmeras benesses oriundas dos procedimentos de reprodução humana medicamente assistida não pode ser olvidada a possibilidade de banalização da técnica. Em razão disso, os princípios bioéticos ${ }^{1}$ são as diretrizes para os cientistas, que devem ter como norte o fundamento da dignidade da pessoa humana.

O princípio da autonomia informa que as pessoas envolvidas têm o direito de saber sobre os objetivos do procedimento, sobre os riscos e benefícios, bem como sobre as formas de acompanhamento e assistência oferecidas pelo cientista, por meio do oferecimento do Termo de Consentimento Livre e Esclarecido, o qual deve ser assinado como medida de autorização para a realização do(s) procedimento(s) (CONSELHO FEDERAL DE MEDICINA, 2013).

O princípio da beneficência e não maleficência é reconhecido como o dever dos profissionais de saúde de fazerem o bem ao paciente e não fazerem o mal (DINIZ, 2014). Esse entendimento surge da lição aprendida com as experiências nazistas, em que eram praticados procedimentos muito distantes do ideário de fazer o bem, caracterizados apenas pela especulação acerca dos resultados.

\footnotetext{
${ }^{1}$ Nesse mote, a referida principiologia é apresentada como resultado do julgamento de Nuremberg, em 1948, em que foram julgados e condenados os profissionais de saúde atuantes nos campos de concentração nazistas e que fizeram uso de pessoas como objetos de uma ciência meramente especulativa (DINIZ, 2014). Com isso, o Código de Nuremberg incorporou a lição ética deste momento histórico, difundindo ao mundo a mensagem de que a utilização de pessoas para fins científicos requer a observação de tais princípios.
} 
Além de preservar as pessoas diretamente envolvidas no processo reprodutivo, a observância dos princípios também protege a atuação profissional. Nesse aspecto, Brauner (2003) destaca como fundamental a promoção de amplo debate sobre as circunstâncias que devem dar cotejo ao recurso da reprodução humana medicamente assistida, bem como quais as responsabilidades dos profissionais da área.

Nesses rumos, Brauner (2003) também refere que, considerando o direito de ter acesso a tratamentos médicos de saúde,

[...] cabe incluir a esterilidade como sendo um problema de saúde reprodutiva e que, portanto, autoriza o recurso à medicina para solucioná-lo, não significando, entretanto, concluir que todas as possibilidades oferecidas pela medicina possam ser aceitas e utilizadas sem limitações pelo homem e pela mulher.

O desenvolvimento da técnica propicia, por meio do diagnóstico pré-implantatório, o conhecimento sobre as características genéticas do embrião e de moléstias futuras, o que possibilita uma intervenção eficaz para promover saúde ao embrião, e permite mesmo a escolha de características genéticas como sexo, cor dos olhos, entre outras, o que pode dar origem a práticas eugenistas, em descompasso com o direito à identidade genética e com a finalidade terapêutica, devendo, portanto, neste último aspecto, ser evitada (DINIZ, 2014).

Algumas situações decorrentes da medicalização da reprodução humana são especialmente delicadas. Cite-se a hipótese de monoparentalidade da mulher que recorre à ciência para ser mãe a partir da utilização de material genético de doador anônimo; o caso da mulher que recorre à utilização de material genético do esposo/companheiro morto, a chamada inseminação artificial post mortem; e, ainda, a circunstância da maternidade de substituição. Tanto no primeiro quanto no segundo caso, a criança é concebida e nasce órfã, carente de pai, conforme Casabona (1994) refere como principal objeção.

No que concerne à maternidade de substituição, apresenta-se como elemento de reflexão a possibilidade da remuneração da mulher que gesta a criança. Nesse diapasão, Brauner (2003) questiona “[...] quais as garantias para que a criança não seja apenas um objeto a ser reivindicado pela mulher que cedeu o útero, confrontando-se ainda as dificuldades para a determinação da maternidade da criança, nos moldes da legislação atual”.

Vale ressaltar o entendimento de Mantovani (apud BRAUNER, 2003), para quem a maternidade de substituição caracteriza ofensa à dignidade da mãe, dado que a locação descaracteriza a maternidade, reduzindo a mulher a mero organismo reprodutor e o nascituro a coisa economicamente apreciável. 
Nesse contexto, destaca-se sobretudo a necessidade de proteção da criança oriunda da reprodução humana medicamente assistida, dada a sua vulnerabilidade peculiar, agravada pelos interesses que possam prevalecer no procedimento.

\section{RESPOSTAS DO DIREITO COMPARADO NA CONTEMPORANEIDADE}

Convivem no mundo diversas percepções acerca da maternidade de substituição: países que a permitem sem ou com poucas restrições, inclusive em contratos comerciais; países que a permitem de forma bastante restritiva; países que a proíbem expressamente em qualquer condição e países que não fazem menção às consequências da técnica. No primeiro grupo estão algumas jurisdições dos Estados Unidos, o Canadá, o Reino Unido, Israel, Grécia, Holanda, Índia e Ucrânia. Ainda assim, nesse grupo há os que possuem legislação específica e aqueles cuja prática é permitida por ausência de proibição ou de restrições. No segundo, podem-se incluir a Argentina e a China, em que a permissão tem uma série de limitações. No terceiro grupo estão aqueles países em que a gestação de substituição é proibida de todas as maneiras, como a França e a Alemanha, que proíbem qualquer tipo de contratação, e a Espanha, que, além da restrição, tem norma expressa de que mãe é aquela que dá à luz (BENICKE, 2013).

No que toca ao Brasil, a circunstância é de inexistência de qualquer legislação sobre o tema, de modo que apenas as resoluções do Conselho Federal de Medicina orientam a prática.

Essas diferenças permitem que as pessoas, para elidir as proibições das suas legislações internas e para levar a cabo o seu projeto parental, busquem um país cuja legislação é mais permissiva. Com isso, proliferou o que se convencionou chamar de "turismo reprodutivo", com inúmeras consequências para o Direito Internacional Privado. Diante da proibição no direito doméstico, resta responder à questão do que fazer com os efeitos de situações ocorridas no estrangeiro, muitas vezes em tentativa de fraude à lei.

Na Argentina, recentemente entrou em vigor o Novo Código Civil e Comercial que, no que concerne à temática, trouxe importantes considerações, como a disposição de que existem necessariamente apenas dois vínculos filiais, seja qual for a natureza da filiação, de acordo com o artigo $558^{2}$ da lei. Ainda, fixou em seu artigo 562 a maternidade/paternidade por vontade

\footnotetext{
2 “ARTICULO 558.- Fuentes de la filiación. Igualdad de efectos. La filiación puede tener lugar por naturaleza, mediante técnicas de reproducción humana asistida, o por adopción.

La filiación por adopción plena, por naturaleza o por técnicas de reproducción humana asistida, matrimonial y extramatrimonial, surten los mismos efectos, conforme a las disposiciones de este Código.

Ninguna persona puede tener más de dos vínculos filiales, cualquiera sea la naturaleza de la filiación” (ARGENTINA, Lei $n^{\circ}$ 26.994, de 7 de outubro de 2014).
} 
procriacional, reconhecendo como pais, a parturiente e o homem ou a mulher que prestou seu consentimento informado. Note-se:

Art. 562.-Voluntad procreacional. Los nacidos por las técnicas de reproducción humana asistida son hijos de quien dio a luz y del hombre o de la mujer que también ha prestado su consentimiento previo, informado y libre en los términos de los artículos 560 y 561, debidamente inscripto en el Registro del Estado Civil y Capacidad de las Personas, con independencia de quién haya aportado los gametos.

A fixação da maternidade é de suma importância para resguardar os interesses da criança em qualquer situação, sobretudo no que tange aos novos contornos propiciados pela maternidade de substituição. Nesse sentido, em alguns sistemas existe uma resposta bem clara: é considerada mãe legal da criança a parturiente no Chile, Alemanha, Áustria, Holanda, Espanha, Portugal, Reino Unido e Suíça. Especialmente na Alemanha, o Código Civil considera a parturiente a mãe legal para todos os efeitos, mesmo no caso de doação de óvulos e maternidade de substituição. No estado da Califórnia, o critério de definição da maternidade é a pretensão e não o parto, de modo a existirem dois conceitos de mãe: a genética e a parturiente. Na França e Japão, diante da inexistência de menção legislativa específica, presume-se mãe a parturiente (GRUENBAUM, 2012). Na Ucrânia, são considerados pais da criança oriunda de maternidade de substituição os contratantes, sejam ou não pais genéticos (BENICKE, 2013).

Muitos sistemas jurídicos da Europa continental consideram nulo o contrato de barriga de aluguel, ou pelo menos inexequível, porque a lei prevê expressamente essa consequência. São os casos de França, Portugal e Espanha. Áustria e Itália proíbem a fecundação heteróloga com óvulos doados, e nesta última são impostas multas severas; na Alemanha tais técnicas são criminalizadas (GRUENBAUM, 2012).

Especialmente a Alemanha adota medida de cautela em razão do histórico de violação dos direitos humanos na Segunda Guerra Mundial. Por isso, a maternidade de substituição é proibida e a mãe da criança é considerada a parturiente, independentemente de ascendência genética. Isso traz repercussões de ordem prática. Gruenbaum (2012) refere que existem muitos pais alemães que gostariam de contratar barriga de aluguel no exterior, onde o contrato é lícito, como na Califórnia e em Nova Iorque, ou em países como Rússia, Ucrânia e Índia.

O mesmo autor refere o caso de um casal alemão que realizou contrato de barriga de aluguel na Ucrânia. A mulher que cedeu seu útero para gestar a criança era casada e nela foi implantado o embrião resultante da fertilização anterior com material genético dos pretensos pais. A legislação ucraniana estabelece que os pais pretendidos são os pais legais da criança e, por conseguinte, a certidão de nascimento foi expedida com os nomes dos pais alemães; entretanto, o pedido de emissão 
de passaporte alemão para as crianças foi negado porque, de acordo com o critério alemão, as crianças teriam adquirido nacionalidade ucraniana. Em outro caso, os pais alemães contrataram barriga de aluguel na Califórnia; os gêmeos nascidos não conseguiram passaporte alemão, de modo que foram conduzidos pelos pais à Alemanha com passaportes estadunidenses (GRUENBAUM, 2012).

Na Argentina, o novo Código Civil e Comercial, que entrou em vigor em $1^{\circ}$ de agosto de 2015, suprimiu a menção ao aluguel de ventre para a finalidade de reprodução assistida. Entretanto, estabeleceu o requisito da vontade procriacional, conforme o artigo 562 referido anteriormente. Notase a desvinculação promovida aos doadores de gametas e a necessária vinculação com a pretensão de ser pai e mãe, bem como o vínculo estabelecido com a parturiente. Os tribunais argentinos já consolidaram jurisprudência, desde o ano de 2013, no sentido de reconhecer inclusive dupla paternidade ou dupla maternidade oriunda de maternidade de substituição.

Lamm (2012) sublinha que o conceito de filiação tem ganhado novos contornos com a desbiologização e a determinação da filiação pelo critério volitivo. Entretanto, uma das grandes questões a serem discutidas diz respeito à maternidade por sub-rogação transfronteiriça.

Destaque-se a circunstância de os autores do projeto parental (os pais que contratam o aluguel de útero) serem nacionais de um país que não permite ou reconhece a prática e, para alcançarem o objetivo de ter um filho, dirigirem-se a um país como Índia ou Nepal, que reconhecem como válido o contrato de maternidade de substituição, adotando legislação favorável ao reconhecimento de filiação pelos pretensos pais ou que, em outro sentido, não adotam o parto como critério de determinação da filiação. De outro lado, se o país de origem dos pais por pretensão não reconhece a técnica, proibindo-a ou a punindo, não reconhece o nascimento em outro país, uma vez que a(s) criança(s) nasceu(ram) de mulher de outra nacionalidade (BENICKE, 2013).

As regras do Conselho Federal de Medicina (CFM) não vedam o uso da gestação de substituição por pessoas estrangeiras, mas as restrições existentes no Brasil - especialmente a que diz respeito ao vínculo de parentesco entre a gestante e os pais - dificultam o seu uso por estrangeiros e por não residentes, desencorajando o "turismo reprodutivo". Não obstante serem os pretensos pais estrangeiros residentes ou não residentes no Brasil, uma vez nascida a criança, de pai ou mãe estrangeira, abre-se a opção de registrar o nascimento perante uma autoridade consular estrangeira. O registro em nome da pretensa mãe poderá ser deferido sem problemas se a legislação do país estrangeiro assim o permitir; ou indeferido, se ferir a sua ordem pública, como ocorreria caso se tratasse da França. Se a opção dos pretensos pais for de efetuar o registro de nascimento perante as autoridades brasileiras, a criança nascida no Brasil será registrada segundo o nosso direito e terá a nacionalidade brasileira assegurada, já que a regra do ius soli a ela se aplica. 
Dessa forma, pelo sistema brasileiro, a regra para a nacionalidade é a do ius soli, ou seja, são brasileiros todos aqueles nascidos no Brasil. No entanto, o sistema é misto, apresentando-se também o critério do ius sanguinis. Assim, os filhos de brasileiros nascidos no exterior serão considerados brasileiros natos em duas hipóteses: a primeira, de forma automática, se houver o registro do nascimento no Consulado do Brasil; a segunda, pelo exercício da opção, quando, na ausência de registro, posteriormente vier a residir no Brasil e fizer a opção perante a justiça federal. Nesse último caso, embora seja necessária a comprovação de certos requisitos, a sentença é meramente declaratória de um estado preexistente (DEL’OLMO, 2002).

A situação contrária - se a criança nascer no exterior de pai ou mãe brasileiros - gera outra ordem de questionamentos, entre os quais destacam-se: a determinação da nacionalidade brasileira das crianças nascidas no exterior, a possibilidade de realizar contratos onerosos de gestação de substituição e, por último, o reconhecimento de decisões estrangeiras para execução no Brasil. Assim, no caso dos nascidos no exterior de pais brasileiros, misturam-se à questão de nacionalidade os problemas relativos ao registro das pessoas naturais, por força das funções cartoriais exercidas pelos consulados brasileiros, que procedem ao registro de nascimento de filhos de brasileiros nascidos no exterior (DEL’OLMO, 2016).

A nacionalidade brasileira da criança, por força da regra de ius sanguinis, exige que um dos pais seja brasileiro. Se a autora do projeto parental não for considerada como mãe pelo direito brasileiro no processo de dúvida, e o pai for desconhecido ou estrangeiro, é possível verificar uma questão de difícil solução para o reconhecimento da nacionalidade brasileira. Nesse caso, se o direito local não utilizar o ius soli, e a nacionalidade brasileira não for atribuída pela lei brasileira, a criança será apátrida, o que significa dizer que ela não possuirá vínculo com qualquer nação. Nesse sentido, Del'Olmo (2009) refere o termo anacional como mais adequado às circunstâncias, pois denota a ideia de uma circunstância passageira na vida da criança.

\section{REGULAÇÃO PELO ORDENAMENTO JURÍDICO BRASILEIRO}

Por tratar-se de temática nova o ordenamento jurídico brasileiro não prevê norma para regulamentá-la. A matéria está orientada de acordo com normas relativas aos contratos atípicos. Nesse aspecto, os requisitos constantes no artigo 104 do Código Civil são elementos a serem observados, destacando-se a capacidade dos agentes, o objeto lícito, possível e determinável do negócio jurídico. Grande parte da doutrina entende que o pacto firmado com o objetivo de contratar um útero é ilícito e, portanto, não possui qualquer validade jurídica. Venosa (2007, p. 230), ao destacar que a lei 
brasileira é lacunosa, discorre sobre o contrato de gestação, como ele próprio denomina, ao observar que “[...] na ausência de norma, entre nós, um contrato oneroso dessa espécie deve ser considerado nulo, porque imoral seu objeto, e a obrigação dele decorrente pode ser considerada, quando muito, obrigação natural”.

Diniz acredita que o fato de efetivar um contrato locatício do útero, envolvendo quantia paga em dinheiro, implicaria um pacto imoral e contrário aos bons costumes, devendo, portanto, ser proibido pela legislação. A autora, quando do contrato gratuito, defende ainda que

[...] sempre haverá a possibilidade da mãe biológica ou hospedeira arrepender-se, tentando o aborto, ou recusar-se a entregar a criança à mãe genética ou à institucional. Imprescindível será vedar ou, então, limitar, rigorosamente, a técnica surrogate gestational mother, ou seja, a prática do uso da mãe substitutiva (DINIZ, 2014, p. 183).

No Brasil, a filiação é determinada pelo parto. Presume-se a maternidade em favor daquela que consta no termo de nascimento do filho, conforme artigos 1.603 e 1.608 do Código Civil, elaborado em consonância com a Declaração de Nascido Vivo, conforme artigo 10, inciso IV, da Lei $\mathrm{n}^{\circ}$ 8.069/90. A paternidade, por sua vez, é compreendida em favor do marido quanto aos filhos nascidos na constância do casamento, ainda que havidos por inseminação artificial heteróloga consentida, de acordo com os artigos 1.597 e 1.600 do Código Civil.

Presume-se, portanto, mãe aquela que deu à luz, independentemente da origem do óvulo, o que se faz em atendimento ao princípio mater semper certa est. Com relação à paternidade, o artigo 1.597, inc. V, do Código Civil de 2002, dispõe que: "Presumem-se concebidos na constância do casamento os filhos: havidos por inseminação artificial heteróloga, desde que tenha prévia autorização do marido”.

Tampouco o Estatuto da Criança e do Adolescente (ECA) possui dispositivo expresso a respeito da determinação da maternidade. Há uma presunção de que é mãe quem dá à luz, como se depreende do artigo 10 do ECA. De particular interesse para essa presunção é o inciso II do referido artigo, em que se exige o registro do recém-nascido e de sua mãe (aqui só podendo ser interpretado como aquela que deu à luz) no momento do parto, inclusive para evitar troca de bebês e outros problemas de identificação. No entanto, não há nenhuma preocupação com a possibilidade de a parturiente não ser a doadora do material genético nem a autora do projeto parental, muito menos de ter havido um consentimento prévio em tratativas sobre gestação de substituição.

Para Venosa (2007, p. 224), deve-se considerar como mãe a mulher que teve seu óvulo fecundado, dado que não se admite transação sobre aspectos familiares. Por outro viés, Gama (2003, 
p. 862-863) comenta que deve prevalecer a vontade que se revelar em prol do melhor interesse do filho.

Conforme disposição da Resolução n 2.013/2013 do CFM, deve haver a garantia do registro civil, pelos pais genéticos, da criança que virá a nascer, devendo a documentação ser providenciada antes mesmo do término da gravidez (CORREGEDORIA NACIONAL DE JUSTIÇA, 2016).

Em face da inexistência de normas específicas sobre a matéria, o Conselho Federal de Medicina produziu a primeira resolução acerca de reprodução humana medicamente assistida - a Resolução CFM n ${ }^{0} 1.957$ de 2010 -, orientadora dos médicos quanto às condutas a serem adotadas diante dos problemas decorrentes da prática da reprodução assistida, normatizando as condutas éticas a serem obedecidas no exercício das técnicas de reprodução assistida. Essa resolução se mostrou satisfatória e eficaz, balizando o controle dos processos de fertilização assistida.

A Resolução $n^{\circ} 2.013$ de 2013, também do CFM, estabelece diretrizes sobre o tema em seu item VII, determinando a utilização das técnicas de reprodução humana medicamente assistida nos casos em que a doadora genética seja estéril ou em caso de contraindicação, ou, ainda, em caso de união homoafetiva. Determina também que a gestação aconteça mediante doação temporária de útero, ou seja, não deve haver remuneração. Nesse sentido, a doadora temporária de útero deve pertencer à família de um dos parceiros em parentesco consanguíneo de até quarto grau, ou seja, deve ser alguém entre mãe (primeiro grau), irmã ou avó (segundo grau), tia (terceiro grau) ou prima (quarto grau). Em qualquer dos casos, deve ser observada a idade máxima de cinquenta anos para gestar a criança (CONSELHO FEDERAL DE MEDICINA, 2013).

As clínicas de reprodução devem manter no prontuário do paciente relatório médico sobre o perfil psicológico da doadora temporária de útero, em que atesta sua adequação emocional e clínica. Também deve constar o Termo de Consentimento Informado, assinado pelos pacientes (pais genéticos) e pela doadora temporária do útero, consignando a motivação do procedimento, como por exemplo, esterilidade, contraindicação ou, ainda, gestação compartilhada entre homoafetivos, hipótese em que inexiste infertilidade (CONSELHO DA JUSTIÇA FEDERAL, 2002).

O contrato firmado entre os pais genéticos e a doadora temporária do útero deverá ser apresentado. Esse requisito identifica exatamente a filiação da criança oriunda do procedimento de reprodução humana medicamente assistida e que nasce do ventre de uma mulher que não pode ser vista como sua mãe em virtude do contrato demonstrado. Ainda, no caso de a doadora temporária de útero ser casada ou convivente em união estável, deve juntar declaração de aprovação do cônjuge ou companheiro, de modo a garantir o registro da criança pelos pais genéticos. Além disso, a referida 
resolução veda a interrupção da gravidez, tendo sido iniciado o processo gestacional, salvo nos casos autorizados em lei ou judicialmente (CONSELHO DA JUSTIÇA FEDERAL, 2002).

Assim, diante da lacuna legislativa e levando em consideração que as normas do Conselho Federal de Medicina possuem caráter deontológico, dotadas de eficácia tão somente em relação aos médicos, faz-se imprescindível desenvolver estudos que permitam uma maior compreensão do papel do Direito na busca da solução de eventuais conflitos, por meio da comunhão dos princípios da ética e do direito (BARUFFI; MORAIS, 2015).

A I Jornada de Direito Civil, de 2002, tratou da filiação quando há intervenção científica na maternidade. O enunciado de número 129 da referida jornada estabeleceu, entre outras coisas, que, nos casos de utilização das técnicas de reprodução assistida, a maternidade será estabelecida em favor daquela que forneceu o material genético (CONSELHO DA JUSTIÇA FEDERAL, 2002).

Assim, compreende-se que o princípio mater semper certa est foi colocado em dúvida porque, no caso da maternidade de substituição, a mulher que gera a criança e a dá à luz não pode ser presumida mãe. Isso se deve ao fato de que a doadora do útero tão somente "contribuiu para que aquele ser gerado pudesse ter viabilidade de nascer, sem a contribuição de suas células germinativas, e que engravidou apenas para ajudar na concepção do filho de outrem, de forma altruísta.” (CANEZIN, 2007, p. 203).

A cessão temporária de útero faz parte das técnicas de reprodução assistida e, sendo assim, conforme o enunciado, é considerada mãe aquela que doou o material genético, e não aquela que emprestou o útero e gestou a criança. Desse modo, comprovada a união ou o casamento, é o que basta para proceder-se ao registro, pois de adoção não se trata.

No próximo tópico, a pesquisa identifica por quais modos os países têm promovido consensos em âmbito internacional.

\section{TENTATIVAS DE ESTABILIZAÇÃO POR MEIO DA CONFERÊNCIA DE HAIA SOBRE DIREITO INTERNACIONAL PRIVADO}

A Conferência da Haia de Direito Internacional Privado (CHDIP) é uma organização intergovernamental de alcance mundial, que iniciou suas atividades em 1893, adquirindo caráter permanente a partir de 1951, quando aprovou seu Estatuto. Conta com 74 países e uma organização de integração regional, a União Europeia, como membros. Dedica-se à harmonização e unificação progressivas do direito internacional privado por meio de competências de regulamentação de diversas matérias, em especial na área do direito de família, de modo que seu principal objetivo é a 
elaboração de instrumentos internacionais para a proteção da infância, assumindo, como vocação global, o tratamento de temas da vida internacional da pessoa (ARAÚJO; POLIDO, 2014).

Entre as várias convenções adotadas na Conferência da Haia destacam-se a Convenção sobre os Aspectos Civis do Sequestro de Menores de 1980, a Convenção sobre Adoção Internacional de 1993 e a Convenção sobre Proteção das Crianças, de 1996. Araújo, Vargas e Martel (2014) expõem que a CHDIP é realizada anualmente no início do mês de abril, momento em que são decididos, pelos seus membros, os temas da agenda e o respectivo mandato. A partir disso, a Associação Americana de Direito Internacional Privado (ASADIP), organização composta de professores e profissionais da área, tem priorizado a discussão prévia dos temas objeto da CHDIP, contribuindo para as negociações multilaterais naquele âmbito.

A temática da maternidade de substituição surgiu na jornada de 2011 da ASADIP, sendo exortada na reunião da CHDIP de 2012, momento em que se ressaltou a importância da questão em face à necessidade de proteção das crianças e vulneráveis abrangidos na maternidade de substituição. Nesses termos, após a elaboração de questionário aos países participantes da CHDIP, seguiu-se o relatório nominado Documento Preliminar n. 03B, de 2014, que pode ser acessado na página da conferência, sob a rubrica de Assuntos Gerais (ARAÚJO; VARGAS; MARTEL, 2014).

O instrumento viabilizou constatar o grande problema da determinação da filiação no plano internacional, dado que a solução interna dos países encontra objeção no plano internacional quando se trata de maternidade de substituição transfronteiriça, carecendo de regulamentação específica. O documento ainda apontou à necessidade de segurança jurídica na comprovação do status legal das crianças por meio da determinação de seu parentesco em caso de maternidade de substituição transfronteiriça, bem como de proteção dos direitos da criança, pais e demais envolvidos no contrato, de acordo com os diplomas de direitos humanos.

Nesses rumos, os riscos inerentes à maternidade de substituição podem ser irremediáveis. Destaquem-se as demonstrações do anexo II da Conferência de Haia de 2015, como o abandono de recém-nascidos, como no caso "baby Gammy”, em que o menino foi abandonado pelos pretensos pais australianos em razão de ter desenvolvido Síndrome de Down; ainda, suspeita-se de tráfico de crianças, dado que um abastado empresário japonês contratou o instituto dezesseis vezes, tendo assim dezesseis filhos decorrentes de maternidade de substituição na Tailândia (CONFERÊNCIA DE HAIA..., 2015).

Outras questões apontadas no anexo II da CHDP dizem respeito ao direito da criança de conhecer as suas origens e a preocupação com as condições em que foi processado o consentimento de barriga de aluguel. Ocorre que os documentos são escritos em inglês e celebrados com mulheres 
que desconhecem a língua, gerando um contrato viciado no que concerne à manifestação de vontade (CONFERÊNCIA DE HAIA..., 2015).

Nesse sentido, há urgência na harmonização das regras de maternidade de substituição e sobre a determinação de parentesco. O que foi acordado até então, entre os Estados, como um passo inicial, diz respeito à criação de regras em caráter de soft law e princípios.

A partir desse entendimento, é possível identificar julgados acerca do reconhecimento de parentesco, demonstrando a influência dos trabalhos de Haia, e que podem ser encontrados no anexo I da Conferência de Haia, conforme segue abaixo.

Na Alemanha, o Tribunal de Justiça Federal, num acórdão recente, reformou a decisão de um tribunal inferior, reconhecendo a nacionalidade alemã para uma criança nascida por maternidade de substituição no estado da Califórnia, nos Estados Unidos da América. O juízo invocou o melhor interesse da criança e o fato de que ela não poderia ser penalizada pelas ações dos pais. Nesse mote, o tribunal rejeitou a hipótese de adoção acolhida pelo tribunal inferior, pois uma adoção nesse sentido implicaria o risco de que os pais mudassem de ideia e não mais desejassem a adoção após o nascimento. Denota-se que haveria possibilidade de os pais por pretensão não terem responsabilidade alguma para com a criança (CONFERÊNCIA DE HAIA..., 2015).

O segundo caso é suíço. Diz respeito ao registro de criança nascida por maternidade de substituição em virtude da relação homoafetiva mantida por dois homens. O juízo declarou que uma decisão contrária poderia gerar consequências negativas para a criança, que não poderia invocar responsabilidade ou eventuais direitos relativos à manutenção da sobrevivência ou herança com relação ao segundo pai por pretensão (CONFERÊNCIA DE HAIA..., 2015).

O terceiro caso é espanhol. A Direção Geral dos Registos e do Notariado emitiu uma circular informando que os registros devem agora voltar a aplicar a instrução própria, do ano de 2010, para uma abordagem mais "liberal” para o reconhecimento de parentalidade de uma criança oriunda de maternidade de substituição. Ao lado disso, em 11 de dezembro de 2014 o Ministro da Justiça espanhol declarou que uma alteração no projeto de lei sobre os registos civis, atualmente em apreciação pelo Parlamento, seria proposta para assegurar que o reconhecimento dos pais por pretensão seja coerente com recentes acórdãos do Tribunal Europeu dos Direitos do Homem (TEDH) (CONFERÊNCIA DE HAIA..., 2015).

O quarto caso é francês. Em uma decisão controversa com data de 12 de dezembro de 2014, o Conselho de Estado confirmou a validade da circular emitida em 25 de janeiro de 2013 pelo Ministro da Justiça, sobre a emissão de certificados de cidadania para filhos nascidos no estrangeiro em decorrência de maternidade de substituição. Com efeito, o Conselho de Estado ponderou que, 
ainda que a lei francesa considere nulo o contrato de maternidade de substituição, não pode privar a criança da nacionalidade francesa. E, fazendo referência aos acórdãos do TEDH, indicou que uma abordagem contrária seria uma "ingerência desproporcionada" no direito da criança e no respeito à vida privada (CONFERÊNCIA DE HAIA..., 2015).

Na Irlanda, em um caso de maternidade de substituição interna, a mãe por pretensão não teve o vínculo de parentesco com a criança oriunda de maternidade de substituição, sendo reconhecida como mãe a mulher que a gestou. A decisão de primeiro grau foi reformada, de modo que o Supremo Tribunal de Justiça declarou a inexistência de lei relacionada, havendo a necessidade de o Parlamento Irlandês preencher o "vazio jurídico”. A decisão foi embasada nos acórdãos do TEDH, no sentido de não realizar distinção entre os interesses dos pais pretendidos e os direitos das crianças (CONFERÊNCIA DE HAIA..., 2015).

Ainda, em virtude dos trabalhos de Haia, Índia e Tailândia comprometeram-se em aprovar, em longo prazo, legislação para resolver alguns dos problemas, demonstrando o alcance dos resultados oriundos das aproximações oferecidas pela Conferência de Haia sobre Direito Internacional Privado. As decisões referidas demonstram a atuação dos Estados em prol do reconhecimento do melhor interesse da criança e respeito aos direitos humanos.

\section{CONSIDERAÇÕES FINAIS}

Em pleno século XXI, a ciência oferece muitos benefícios à humanidade, como a possibilidade de ter filhos com a doação de material genético de terceiro e, ainda, por meio da gestação por outrem, objeto de estudo nesta pesquisa. Considerando o estado da técnica no que toca à reprodução humana medicamente assistida, especialmente a maternidade de substituição, é possível referir que, além do tráfico e venda de crianças e da vulnerabilidade extrema das mulheres que acordam gestar filhos de outrem, a situação das crianças anacionais é outra grande preocupação.

Ocorre que as regras de direito podem gerar contingência quando os casos têm repercussão transnacional, como quando pais alemães buscam contratar maternidade de substituição na Índia. Nesse sentido, de acordo com a legislação indiana, a criança adquirirá ao nascer a nacionalidade de seus pais alemães, enquanto que de acordo com a legislação da Alemanha a criança adquirirá a nacionalidade indiana. O resultado do conflito é uma criança apátrida, ou seja, sem nacionalidade.

A anacionalidade é condição que não pode ser tolerada pelos Estados em tempos de globalização e mobilidade. Consiste em ausência de nacionalidade e em violação da dignidade humana, pois a criança acaba sendo penalizada por algo que não escolheu ou de que seus pais não 
tinham total consciência. Note-se que nesse aspecto o direito interno sofre limitações para resolver os problemas oriundos da maternidade de substituição transnacional, e por isso ressalta-se a necessidade de cooperação multilateral para que, em uníssono, sejam garantidos os direitos das crianças.

No contexto dos avanços tecnológicos decorrentes da medicalização da reprodução humana é preciso ponderar as opções pessoais dos indivíduos, a partir das possibilidades hoje permitidas pela ciência, pois a maternidade a partir da gestação de substituição é uma realidade que não pode mais ser ignorada. No entanto, dentro dessa realidade, é preciso definir os limites da autonomia privada dos indivíduos.

A Argentina demonstrou esforços em seu novo Código Civil e Comercial, que teve entrada em vigor em agosto de 2015, no qual previu o estabelecimento de duplo vínculo de filiação: considerou a mulher gestante como necessariamente mãe da criança, além de reconhecer o vínculo de filiação que diz respeito ao homem ou à mulher que contratou maternidade de substituição.

No caso do Brasil constata-se a inexistência de normatização, verificando-se apenas as resoluções do Conselho Federal de Medicina a respeito. Assim, diante de tamanha lacuna legislativa, qualquer tentativa deve contemplar a gratuidade e/ou onerosidade do contrato, a fixação da maternidade por força do contrato, o que implica o registro de filiação da criança independentemente do nome da mulher constante na declaração de nascido vivo, e, ainda, as implicações decorrentes da aquisição de nacionalidade.

Outro aspecto que deve ser ponderado pelo legislador brasileiro diz respeito a determinar com clareza as limitações impostas à mulher gestante no que toca à sua relação com a criança e os pais. Além disso, com relação aos aspectos médicos cabe prever a fiscalização das clínicas envolvidas na técnica, e também quanto à observância das normas que regulamentam a prática médica bioética. Ressalta-se, ainda, a urgência de regulamentação que esteja atenta ao turismo reprodutivo.

No plano internacional, a Conferência de Haia tem propiciado o debate e aproximações no entendimento dos Estados, como demonstram os julgamentos elencados no anexo II da Conferência: países como Alemanha, Espanha, Suíça, França e Irlanda reconheceram o vínculo de filiação dos pais pretendidos, bem como a devida nacionalidade de seus países. No entanto, do que já foi feito até agora, resta claro que é preciso avançar em um instrumento de caráter multilateral que traga segurança jurídica às crianças no que diz respeito aos seus laços de parentesco, quando são obrigadas a se movimentar fora do seu país de origem. Regras de direito internacional privado uniformes, sobre a determinação do parentesco legal, são necessárias tanto no contexto de uma concepção tradicional como daquela obtida por meio da gestação de substituição. 
Por derradeiro, deve-se mencionar que os estudos empreendidos pela Conferência de Haia têm propiciado importantes contribuições para a temática, dado que em países de tradição ius sanguinis já aconteceram casos de reconhecimento do vínculo de filiação para os pais por pretensão. Tais circunstâncias também servem para o caso brasileiro, no sentido de se legislar sobre a reprodução humana medicamente assistida e, especialmente, sobre a maternidade de substituição.

\section{REFERÊNCIAS}

ARAÚJO, Nadia de; POLIDO, Fabrício Bertini Pasquot. Contribuições da ASADIP para o desenvolvimento do trabalho da Conferência da Haia de Direito Internacional Privado: Balanço das Reuniões Preparatórias para Reunião Anual de Assuntos Gerais. In: CONPEDI. (Org.). (Re) Pensando o Direito: Desafios para a Construção de novos Paradigmas: Direito internacional. 1. ed. Florianópolis: CONPEDI, 2014, v. 1, p. 230-254.

ARAÚJO, Nadia de; VARGAS, Daniela Trejo; MARTEL, Letícia de Campos Velho. Gestação de substituição: regramento no direito brasileiro e seus aspectos de direito internacional privado. 2014. Disponível em: <https://goo.gl/Pqqd8Q>. Acesso em: 5 jun. 2016.

ARGENTINA. Lei n 26.994, de 7 de outubro de 2014. Código Civil y Comercial de la Nación. Disponível em: <https://goo.gl/sRkN4y>. Acesso em: 11 jan. 2017.

BARUFFI, Helder; MORAIS, Mariane H. de. Maternidade de substituição: reflexões a partir do princípio da dignidade da pessoa humana em razão da lacuna normativa do direito brasileiro. Derecho y Cambio Social, Lima, Peru, n. 39, ano XII, 2015. Disponível em: <https://goo.gl/aNXhB9>. Acesso em: 1 jun. 2015.

BENICKE, Christoph. Maternidade por substituição do direito internacional privado. Palestra UFRGS, 2013.

BÍBLIA SAGRADA. 34. ed. Tradução Centro Bíblico Católico. São Paulo: Paulinas, 2004.

BRASIL. Lei n ${ }^{\circ}$ 8.069, de 13 de julho de 1990. Dispõe sobre o Estatuto da Criança e do Adolescente e dá outras providências. Disponível em: <https://goo.gl/XE9ht>. Acesso em: 18 jun. 2016.

BRAUNER, Maria Cláudia Crespo. Direito, sexualidade e reprodução humana: conquistas médicas e debate bioético. Rio de Janeiro: Renovar, 2011.

BRAUNER, Maria Cláudia Crespo. Novas tecnologias reprodutivas e projeto parental. Contribuição para o debate no Direito brasileiro. 2003. Disponível em: <https://goo.gl/1sC8ym>. Acesso em: 6 ago. 2016.

CANEZIN, Claudete Carvalho. O direito dos pais biológicos em registrar seu filho gerado por mãe hospedeira. In: HIRONAKA, Giselda Maria Fernandes Novaes (Coord.). A outra face do Poder Judiciário: decisões inovadoras e mudanças de paradigmas. V. 2. Belo Horizonte: Del Rey, 2007. 
CASABONA, Carlos Maria Romeo. El derecho y la Bioética ante los límites de la vida humana. Madrid: Centro de Estudios Ramón Areces, 1994.

CONFERÊNCIA DE HAIA SOBRE DIREITO INTERNACIONAL PRIVADO. Documento preliminar $\mathbf{n}^{\circ}$ 3: projeto de maternidade de substituição, notas de atualização. 2015. Disponível em: $<$ https://goo.gl/1NFrtu>. Acesso em: 6 jun. 2016.

CONSELHO DA JUSTIÇA FEDERAL. Jornadas de Direito Civil. 2002. Disponível em: $<$ https://goo.gl/H3VCQt>. Acesso em: 6 jun. 2015.

CORREGEDORIA NACIONAL DE JUSTIÇA. Provimento $\mathbf{n}^{\circ}$ 52, de 14 de março de 2016. Disponível em: <https://goo.gl/SG8wZG>. Acesso em: 11 out. 2016.

CONSELHO FEDERAL DE MEDICINA. Resolução $\mathbf{n}^{\circ}$ 2.013/2013. Disponível em: $<$ https://goo.gl/i1FdW>. Acesso em: 18 ago. 2016.

DEL'OLMO, Florisbal de Souza. Barriga de aluguel no exterior e a aquisição da nacionalidade brasileira. Revista Brasileira de Direito Animal, Salvador, v. 11, n. 22, p. 177-200, maio-ago. 2016. Disponível em: <https://goo.gl/ehjWoy>. Acesso em: 20 set. 2016.

DEL'OLMO, Florisbal de Souza. A Emenda Constitucional no. 54 e o resgate da cidadania brasileira para filhos de nacionais nascidos no estrangeiro. In: Anuario mexicano de derecho internacional, v. 9, México, ene. 2009.

DEL’OLMO, Florisbal de Souza. Curso de direito internacional público. Rio de Janeiro: Forense, 2002.

DIAS, M. H. M.; PITERI, S. H. O. R. (Org.). A literatura do Outro e os Outros da literatura. São Paulo: Editora UNESP, 2010.

DINIZ, Maria Helena. O estado atual do biodireito. 9. ed. rev. aum. e atual. São Paulo: Saraiva, 2014.

GAMA, Guilherme Calmon Nogueria da. O Biodireito e as relações parentais. Rio de Janeiro: Renovar, 2003.

GRUENBAUM, Daniel. Foreign Surrogate Motherhood: Mater Semper Certa Erat. American Journal of Comparative Law, v. 60, p. 475-506, 2012. Disponível em: <https://goo.gl/1RhEij>. Acesso em: 2 jun. 2015.

HUXLEY, Aldous. Admirável mundo novo. Tradução Lino Vallandro e Vidal Serrano. 2. ed. 16. reimp. São Paulo: Globo, 2003.

JAYME, Erik. Visões para uma teoria pós-moderna do direito comparado. RT 759/24, janeiro/1999.

JAYME, Erik. Direito internacional privado e cultura pós-moderna. Cadernos do Programa de PósGraduação em Direito/UFRGS, Porto Alegre, v. 1, n. 1, p. 105-114, mar. 2003. 
LAMM, Eleonora. La importancia de la voluntad procreacional en la nueva categoría de filiación derivada de las técnicas de reproducción assistida. Revista de Bioética y Derecho, n. 24, enero 2012, Observatori de Bioètica i Dret, Barcelona, p. 76-91, Disponível em: <https://goo.gl/iuRGXw>. Acesso em: 2 jun. 2015.

MEIRELLES, Jussara Maria Leal. Gestação por outrem e determinação da maternidade. Curitiba: Gêneses, 1998.

SANDEL, Michael J. Contra a perfeição: ética na era da engenharia genética. Tradução Ana Carolina Mesquita. Rio de Janeiro: Civilização Brasileira, 2013.

SARLET, Ingo Wolfgang. Dignidade da pessoa humana e direitos fundamentais na Constituição Federal de 1988. Porto Alegre: Livraria do Advogado, 2001.

SCARPARO, M. S. Fertilização assistida: questão aberta - aspectos científicos e legais. Rio de Janeiro: Forense Universitária, 1991.

VENOSA, Silvio. Direito civil: direito de família. 7. ed. São Paulo: Atlas, 2007.

Taciana Damo Cervi

Doutoranda em Direito pela UFRGS, mestre em Direito pela UCS. Professora na Universidade Regional Integrada do Alto Uruguai e das Missões - URI - Santo Ângelo, nas disciplinas de Direito Civil parte geral e Biodireito. Assessora técnica no Comitê de Ética em Pesquisa com Humanos na mesma universidade. Pesquisadora na área de Biodireito, Bioética e Direito Civil.E-mail: taciana@santoangelo.uri.br

Sinara Camera

Doutora em Direito Público pela Universidade do Rio dos Sinos (Unisinos) com período de doutoramento na Universidade de Sevilla (Espanha), realizado com bolsa PDSE - Capes. Mestre em Integração Latino-Americana pela Universidade Federal de Santa Maria (Mila/UFSM). Bacharel em Ciências Sociais e Jurídicas pelo Instituto de Ensino Superior de Santo Ângelo (Iesa). Professora no Curso de Direito das Faculdades Integradas Machado de Assis (Fema) nas áreas de Teoria do Estado, Direitos Humanos, Direito Internacional Público e Direito Comunitário e da Integração. Pesquisadora na área de Direito Internacional dos Direitos Humanos, de Teoria do Estado e de Cooperação Internacional. E-mail: aiacamera@hotmail.com 